\title{
Quadrivalent Human Papillomavirus (HPV) Types 6, 11, 16, 18 Vaccine for the Prevention of Genital Warts in Males ${ }^{\dagger}$ Profile Report
}

\author{
Karly P. Garnock-Jones ${ }^{1}$ and Anna R. Giuliano ${ }^{2}$ \\ 1 Adis, Auckland, New Zealand \\ 2 Department of Cancer Epidemiology and Genetics, H. Lee Moffitt Cancer Center and Research \\ Institute, Tampa, FL, USA
}

Human papillomavirus (HPV) infection has a well established association with the development of genital warts and many types of cancer, including cervical, anal, oropharyngeal, and penile cancer. ${ }^{[2,3]}$ It is the most common sexually transmitted infection in the US, ${ }^{[2]}$ with an annual prevalence of $1 \%$ of the sexually active population. ${ }^{[3]}$ It has been estimated that $80 \%$ of sexually active women will acquire HPV infection by the time they are aged 50 years. ${ }^{[2]}$ Rates among men are also high, with estimates of $\approx 65-70 \%$ of males being infected with HPV. ${ }^{[4]}$ Young people appear to be most at risk, with $74 \%$ of annual HPV infections occurring in men and women aged 14-24 years. ${ }^{[2]}$

While most HPV infections are transient, ${ }^{[2,3]}$ $\approx 10 \%$ lead to persistent infection. ${ }^{[2]}$ Approximately 40 of the $>100$ known HPV types have been shown to infect the anogenital tract. ${ }^{[2,3]}$ Fifteen of these have been identified as high-risk (including HPV 16 and 18) and twelve as low-risk (including HPV 6 and 11);:[2] HPV 6 and 11 are strongly associated with genital warts ( $>90 \%$ association $\left.{ }^{[3]}\right)$, while HPV 16 and 18 are strongly associated with cervical and anogenital cancers. ${ }^{[2,3]}$ A total of $99.7 \%$ of cervical cancers have detectable levels of HPV DNA, ${ }^{[2]}$ and almost $90 \%$ of vaginal cancers are associated with HPV. ${ }^{[5]}$ In men, $80-85 \%$ of anal cancers ${ }^{[5]}$ and al- most $50 \%$ of penile cancers ${ }^{[5,6]}$ are associated with HPV infection.

The rate of new cases of anogenital warts is increasing; currently, more than 500000 new cases occur in the US annually, and a 2003 estimate found that $\approx 1.4$ million people in the US had genital warts. ${ }^{[3]}$ Moreover, results from a recent study have suggested that the incidence and prevalence of genital warts may be becoming higher in men than in women. ${ }^{[7]}$ The societal burden of genital warts, in terms of both cost and loss of quality of life, is significant. ${ }^{[8-10]}$

The quadrivalent HPV types 6, 11, 16, 18 vaccine $\left(\right.$ Gardasil $^{\circledR}$; hereafter referred to as the quadrivalent HPV vaccine) is a noninfectious recombinant vaccine and comprises purified virus-like particles derived from the L1 capsid proteins of HPV types 6 , 11, 16, and 18. ${ }^{[11]}$ Each dose contains approximately $20,40,40$, and $20 \mu \mathrm{g}$ of each virus-like particle type, respectively, and includes $225 \mu \mathrm{g}$ of amorphous aluminium hydroxyphosphate sulfate adjuvant (AAHS). ${ }^{[11]}$ It was approved in females in the US in $2006^{[12]}$ for the prevention of various diseases caused by HPV types $6,11,16$, and 18 , and has recently been approved in males for the prevention of genital warts caused by HPV types 6 and 11.[11] Over 61 million doses of the

$\dagger$ Adapted and reproduced from the original article published in Drugs 2011; 71 (5): 591-602.[1] 
Table I. Features and properties of the quadrivalent human papillomavirus (HPV) types $6,11,16,18$ vaccine $\left(\text { Gardasil }{ }^{\circledR}\right)^{[1]}$

Featured indication

Prevention of genital warts (condyloma acuminata) caused by infection with HPV types 6 and 11 in males aged 9-26y

Vaccine composition

Virus-like particles (VLPS) derived from the L1 capsid proteins of HPV types 6, 11, 16, and 18

Formulated with a proprietary amorphous aluminium hydroxyphosphate sulfate adjuvant $(225 \mu \mathrm{g}$ per dose)

Dosage and administration

Route of

Intramuscular injection

administration

$0.5 \mathrm{~mL}$ (containing 20,40,40, and $20 \mu \mathrm{g}$ of VLPs for HPV types 6,11 , 16 , and 18 , respectively)

Administration

Three-dose regimen; injections at

schedule

months 0,2 , and 6

Most common adverse events ( $\geq 5 \%$ of males aged 9-26 years receiving the quadrivalent $\mathrm{HPV}$ vaccine)

Injection-site pain, injection-site erythema, injection-site swelling, headache, pyrexia

quadrivalent HPV vaccine have been distributed worldwide. ${ }^{[13]}$ The features and properties of the quadrivalent HPV vaccine are presented in table I. ${ }^{[1]}$

The quadrivalent vaccine has demonstrated efficacy in the prevention of cervical, vulvar, and vaginal cancer, genital warts, and precancerous or dysplastic lesions caused by HPV types 6,11 , 16 , and 18 in females, ${ }^{[11]}$ and estimates show that, as well as being potentially cost effective, ${ }^{[14]}$ national vaccination programs targeting adolescent females and young women can be expected to result in decreased incidences of HPV infection ${ }^{[15]}$ and genital warts ${ }^{[16]}$ in both females and heterosexual males (HM) as a result of herd immunity. ${ }^{[16]}$ However, no change was predicted for men who have sex with men (MSM; a group with a high prevalence of HPV infection ${ }^{[17]}$ ) or females outside the age range for vaccination. ${ }^{[16]}$

Various arguments exist in favor of nationwide vaccination of males as well as females, including the increased likelihood of herd immunity, increased effect in the MSM population, and decreased incidence of HPV-associated disease in males (potentially more so than is associated with decreased transmission of the virus from females). ${ }^{[12,18]}$ While one analysis indicated that the vaccination of males as well as females may not be cost effective in the US, ${ }^{[19]}$ this study assumed a higher vaccination rate (75\% in both sexes) than is currently observed in women in the US and in most other countries, ${ }^{[12]}$ mainly focused on the prevention of cervical cancer (only including other factors [e.g. genital warts, lower vaccination rates] in secondary scenarios), ${ }^{[19]}$ and did not specifically include MSM in any analyses. ${ }^{[19]}$ Other analyses were more positive, one citing substantial public health benefits and cost effectiveness of vaccinating males aged 9-26 years against HPV 6-, 11-, 16-, and 18-related diseases, ${ }^{[20]}$ another finding that vaccinating MSM was a cost-effective method for prevention of HPV-related anal cancer and genital warts. ${ }^{[21]}$ It has been suggested that if vaccination of one sex falls below $75 \%$, both sexes will need to be vaccinated to achieve herd immunity. ${ }^{[18]}$ Nevertheless, debate continues as to the necessity of vaccination in males.

The quadrivalent HPV vaccine is a recombinant vaccine comprising purified virus-like particles derived from the L1 capsid proteins of HPV types $6,11,16$, and $18 .^{[11]}$

The vaccine was highly immunogenic in males. ${ }^{[22-25]}$ Geometric mean titers (GMTs) and seroconversion rates for all four HPV types at month 7 in males aged $10-15$ years were noninferior to those in females aged 16-23 years, ${ }^{[22]}$ and those in males aged 9-15 years were noninferior to those in females aged 9-15 years. ${ }^{[23]}$ In addition, GMTs and seroconversion rates in males aged 16-26 years receiving the vaccine were higher than in those receiving AAHS control. ${ }^{[25]}$

Immunogenicity was generally maintained in the longer term (18-37 months), although antibody levels decreased substantially, compared with the levels at month $7 .^{[11,23,25]}$

Immunogenicity of the quadrivalent HPV vaccine was not affected by coadministration with a diptheria, tetanus, pertussis, and poliomyelitis vaccine $\left(\right.$ Repevax $\left.{ }^{\circledR}\right),{ }^{[26}$ a meningococcal polysaccharide conjugate vaccine $\left(\right.$ Menactra $\left.{ }^{\circledR}\right)$ plus a tetanus, diptheria, and pertussis vaccine $\left(\right.$ Adacel $\left.^{\mathrm{TM}}\right){ }^{[27]}$ or a tetanus, diptheria, and pertussis vaccine (Boostrix ${ }^{\mathrm{TM}}$ ) plus an investigational quadrivalent meningococcal glycoconjugate vaccine ${ }^{[28]}$ in three randomized, open-label trials in mixed-sex populations aged 
$11-17,{ }^{[26]} 10-17,,^{[27]}$ and $11-18^{[28]}$ years. Moreover, the immune responses related to the other vaccines being investigated were also noninferior with concomitant versus sequential administration. ${ }^{[26-28]}$ Additionally, neither of the immune responses associated with the quadrivalent HPV vaccine or a hepatitis $\mathrm{B}$ vaccine (Recombivax $\mathrm{HB}^{\circledR}$ ) were affected when the vaccines were coadministered in a population of women aged 16-23 years. ${ }^{[29]}$

After a median follow-up of 2.9 years, the quadrivalent HPV vaccine was significantly more effective than AAHS control at decreasing the incidence of HPV 6-, 11-, 16-, or 18-related external genital lesions (the primary endpoint) in a randomized, double-blind, placebo-controlled, multicenter study in males aged $16-26$ years. ${ }^{[24]}$ The vaccine was $90.4 \%$ effective $(95 \%$ CI $69.2,98.1)$ for this endpoint. The most common clinical endpoint was HPV 6- and 11-related condyloma; efficacy was robust against these lesions. ${ }^{[24]}$ No cases of penile/ perianal/perineal cancer were reported in either group. ${ }^{[25]}$

The vaccine is also expected to be protective against genital warts in males aged 9-15 years, as the immune response in males of this age group was noninferior to that in males aged $16-26$ years. ${ }^{[25]}$

Efficacy of the quadrivalent HPV vaccine was also shown with regard to the prevention of persistent and incident HPV infection. ${ }^{[24]}$

The quadrivalent HPV vaccine was generally well tolerated in males aged 9-26 years. ${ }^{[22-24]}$ The most common adverse events reported were injection-site related, ${ }^{[22-24]}$ and most of these were of mild to moderate severity. ${ }^{[1]}$ Overall, coadministration of the quadrivalent HPV vaccine with other vaccines was generally well tolerated. ${ }^{[26-29]}$

\section{Acknowledgments and Disclosures}

The full text article ${ }^{[1]}$ from which this profile report was derived was reviewed by $\boldsymbol{K}$. $\boldsymbol{K o h l}$, Division of Global Migration and Quarantine, National Center for Emerging and Zoonotic Infectious Diseases, Centers for Disease Control and Prevention, Atlanta, GA, USA; A. Moore, Arlington Center for Dermatology, Department of Dermatology, Baylor University Medical Center, Dallas, TX, USA, and Department of Dermatology, University of Texas Medical Branch at Galveston, Galveston, TX, USA.

The manufacturer of the agent under review was offered an opportunity to comment on the original article during the peer review process. Changes based on any comments received were made on the basis of scientific and editorial merit. The preparation of the original article and this profile report was not supported by external funding.

A. Giuliano is on the Speaker's Bureau of Merck and Co, Inc., and is a consultant to Merck and Co, Inc.

\section{References}

1. Garnock-Jones KP, Giuliano AR. Quadrivalent human papillomavirus (HPV) types $6,11,16,18$ vaccine for the prevention of genital warts in males. Drugs 2011; 71 (5): 591-602

2. Hutchinson DJ, Klein KC. Human papillomavirus disease and vaccines. Am J Health Syst Pharm 2008 Nov 15; 65 (22): 2105-12

3. Hsueh PR. Human papillomavirus, genital warts, and vaccines. J Microbiol Immunol Infect 2009 Apr; 42 (2): 101-6

4. Giuliano AR, Salmon D. The case for a gender-neutral (universal) human papillomavirus vaccination policy in the United States: point. Cancer Epidemiol Biomarkers Prev 2008; 17 (4): 805-9

5. Giuliano AR, Tortolero-Luna G, Ferrer E, et al. Epidemiology of human papillomavirus infection in men, cancers other than cervical and benign conditions. Vaccine 2008; 26 Suppl. 10: K17-28

6. Miralles-Guri C, Bruni L, Cubilla AL, et al. Human papillomavirus prevalence and type distribution in penile carcinoma. J Clin Pathol 2009 Oct; 62 (10): 870-8

7. Kliewer EV, Demers AA, Elliott L, et al. Twenty-year trends in the incidence and prevalence of diagnosed anogenital warts in Canada. Sex Transm Dis 2009; 36 (6): 380-6

8. Lacey CJ, Lowndes CM, Shah KV. Chapter 4: burden and management of non-cancerous HPV-related conditions. HPV-6/11 disease. Vaccine 2006 Aug; 24 Suppl. 3: S35-41

9. Hillemanns P, Breugelmans JG, Gieseking F, et al. Estimation of the incidence of genital warts and the cost of illness in Germany: a cross-sectional study. BMC Infect Dis 2008; 8: 76

10. Woodhall SC, Jit M, Cai C, et al. Cost of treatment and QALYs lost due to genital warts: data for the economic evaluation of HPV vaccines in the United Kingdom. Sex Transm Dis 2009 Aug; 36 (8): 515-21

11. Merck and Co. Gardasil ${ }^{\circledR}$ (human papillomavirus quadrivalent [types $6,11,16$, and 18] vaccine, recombinant, intramuscular injection): US prescribing information [online]. Available from URL: http://www.merck.com/prod uct/usa/pi_circulars/g/gardasil/gardasil_pi.pdf [Accessed 2010 May 28]

12. Palefsky JM. Human papillomavirus-related disease in men: not just a women's issue [published erratum appears in J Adolesc Health 2010; 46: 614]. J Adolesc Health 2010; 46 Suppl. 4: S12-9

13. Australian Government, Department of Health and Ageing, Therapeutic Goods Administration. Gardasil (human papillomavirus vaccine) [online]. Available from URL: http:// www.tga.gov.au/safety/alerts-medicine-gardasil-070624.htm [Accessed 2012 Aug 20]

14. Jit M, Choi YH, Edmunds WJ. Economic evaluation of human papillomavirus vaccination in the United Kingdom. BMJ 2008; 337: a769 
15. Smith MA, Canfell K, Brotherton JML, et al. The predicted impact of vaccination on human papillomavirus infections in Australia. Int J Cancer 2008; 123 (8): 1854-63

16. Fairley CK, Hocking JS, Gurrin LC, et al. Rapid decline in presentations of genital warts after the implementation of a national quadrivalent human papillomavirus vaccination programme for young women. Sex Transm Infect 2009 Dec; 85 (7): 499-502

17. Heiligenberg M, Michael KM, Kramer MA, et al. Seroprevalence and determinants of eight high-risk human papillomavirus types in homosexual men, heterosexual men, and women: a population-based study in Amsterdam. Sex Transm Dis 2010 Aug 19; 37 (11): 672-80

18. Kubba T. Human papillomavirus vaccination in the United Kingdom: what about boys? Reprod Health Matters 2008 Nov; 16 (32): 97-103

19. Kim JJ, Goldie SJ. Cost effectiveness analysis of including boys in a human papillomavirus vaccination programme in the United States. BMJ 2009; 339: b3884

20. Elbasha EH, Dasbach EJ. Impact of vaccinating boys and men against HPV in the United States. Vaccine 2010 Oct; 28 (42): 6858-67

21. Kim JJ. Targeted human papillomavirus vaccination of men who have sex with men in the USA: a cost-effectiveness modelling analysis. Lancet Infect Dis 2010 Dec; 10 (12): 845-52

22. Block SL, Nolan T, Sattler C, et al. Comparison of the immunogenicity and reactogenicity of a prophylactic quadrivalent human papillomavirus (types $6,11,16$, and 18) L1 virus-like particle vaccine in male and female adolescents and young adult women. Pediatrics 2006 Nov; 118 (5): 2135-45

23. Reisinger KS, Block SL, Lazcano-Ponce E, et al. Safety and persistent immunogenicity of a quadrivalent human papillomavirus types $6,11,16,18 \mathrm{Ll}$ virus-like particle vaccine in preadolescents and adolescents: a randomized controlled trial. Pediatr Infect Dis J 2007 Mar; 26 (3): 201-9

24. Giuliano AR, Palefsky JM, Goldstone S, et al. Efficacy of quadrivalent HPV vaccine against HPV infection and dis- ease in males. N Engl J Med 2011 Feb; 354 (5): 401-411. Plus supplementary material available from URL: http:/ www.nejm.org/doi/full/10.1056/NEJMoa0909537 [Accessed $2011 \mathrm{Feb} 4]$

25. US FDA. Clinical review of biologics license application supplement STN\# 125126/1297.0: male indication for GARDASIL [online]. Available from URL: http://www. fda.gov/downloads/BiologicsBloodVaccines/Vaccines/App rovedProducts/UCM190977.pdf [Accessed 2010 Jun 1]

26. Vesikari T, Van Damme P, Lindblad N, et al. An open-label, randomized, multicenter study of the safety, tolerability, and immunogenicity of quadrivalent human papillomavirus (types 6/11/16/18) vaccine given concomitantly with diphtheria, tetanus, pertussis, and poliomyelitis vaccine in healthy adolescents 11 to 17 years of age. Pediatr Infect Dis J 2010 Apr; 29 (4): 314-8

27. Reisinger KS, Block SL, Collins-Ogle M, et al. Safety, tolerability, and immunogenicity of Gardasil given concomitantly with Menactra and Adacel. Pediatrics 2010; 125 (6): 1142-51

28. Arguedas A, Soley C, Loaiza C, et al. Safety and immunogenicity of one dose of MenACWY-CRM, an investigational quadrivalent meningococcal glycoconjugate vaccine, when administered to adolescents concomitantly or sequentially with Tdap and HPV vaccines. Vaccine $2010 \mathrm{Apr}$ 19; 28 (18): 3171-9

29. Wheeler CM, Bautista OM, Tomassini JE, et al. Safety and immunogenicity of co-administered quadrivalent human papillomavirus (HPV)-6/11/16/18 L1 virus-like particle (VLP) and hepatitis B (HBV) vaccines. Vaccine 2008 Jan 30; 26 (5): 686-96

Correspondence: Karly P. Garnock-Jones, Adis, 41 Centorian Drive, Private Bag 65901, Mairangi Bay, North Shore 0754, Auckland, New Zealand.

E-mail: demail@springer.com 